\title{
IMPLEMENTATION AND EVALUATION OF A COGNITIVE APPRENTICESHIP APPROACH TO CIVIL ENGINEERING
}

Poitras, G. J.; *Poitras, E. G.

Department of Civil Engineering, Université de Moncton, NB, Canada gerard.poitras@umoncton.ca

\section{INTRODUCTION}

From the onset of formal engineering education, engineering curricula have been based largely on science and mathematical knowledge. Applied subject based learning is a common teaching model in engineering education programs today. The professor passes information to the students, the newly acquired knowledge is applied to specific problems and communication between students and professor (and between students themselves) is limited. Furthermore, the engineering curriculum may neglect the critical skills that are necessary for a graduate student to be successful in the workplace, namely the reasoning and strategies that experts employ when they acquire knowledge or put it to work to solve complex real-life tasks (Collins et al., 1991). The purpose of this study is to design an optimal learning environment that meets the requirements of particular learning styles. We investigate a novel approach to teaching civil engineering, referred to as cognitive apprenticeship (Collins et al., 1991; Collins, 2006). The cognitive apprenticeship embeds learning in activities and makes deliberate use of the social and physical context. It tries to acculturate students into authentic practices through activity and social interactions in a way similar to that evident in craft apprenticeships. Collins et al. (1991) have developed a conceptual framework to design learning environments according to four principles regarding content, method, sequence and sociology.

Traditional teaching practices do not sufficiently emphasize the reasoning and strategies that experts use to acquire knowledge and apply it to solve real-life problems (Collins et al., 1991), nor do they address students' individual differences with regard to learning style preferences (Lowery, 2009). Therefore, the cognitive apprenticeship approach was implemented and evaluated to teach civil engineering and compared with a traditional teaching approach.

Two experiments were conducted in order to compare the traditional and cognitive apprenticeship approach. The first was done with one group of students attending two different courses taught by the same professor. The first course was taught according to a traditional approach and the other, by a cognitive apprenticeship approach. The second experiment was conducted with a different group of students within the same course where one section of the course was taught according to a traditional approach and the other with a cognitive apprenticeship approach.

\section{METHODS}

At the beginning of the experiment, the students were asked to complete Honey and Mumford's learning style questionnaire (Honey and Mumford, 1992) and were subsequently classified according to their learning styles. The examination of students' learning styles shows a wide variety of preferred approaches to learning. Furthermore, at the end of the study, students completed an evaluation questionnaire. The questionnaire is designed to compare the traditional and cognitive apprenticeship methods with regard to a list of evaluation criteria.

In the first experiment, twenty five students enrolled in their fourth year of civil engineering volunteered to participate in the study. The group attended two courses: a structural analysis course that was delivered in a traditional way and a structural steel design course where a cognitive apprentice approach was used. For the second experiment, seventeen students in their third year of civil engineering volunteered to participate in the study. The group attended a structural analysis course where the first half of the course was delivered in a traditional way and the second half was delivered according to the cognitive apprenticeship approach.

For the structural steel design course, the students were required to complete a project that consisted of designing a two storey steel building where the geometry, material, size and location (size and location was unique to each group) was chosen beforehand. The main objective of the project was presented at the beginning of the course. The students were given access to all the course material (handout, design books, codes, standards, computers, etc). Before each class, the students were asked to read the course material relating to the design to be realized in the classroom. A typical class would start with a 10 to 15 minute revision of the relevant material by the professor followed by a question period, after which students would start the design process of the specific objective to be realized. At the beginning of the class, goals are set by the professor and the design results for each group obtained during the session are written down on the board. At the end of the class, a discussion with the students about the results obtained is undertaken. Thus, all of the students can benefit from the correct or/and incorrect design of others. Group leaders are appointed for each class. They are responsible for the work accomplished by the group and are assigned to ask the questions on the group's behalf. Students are encouraged to find the answers to questions within their group. When necessary, the professor answers questions or gives guidance to help students find the answers themselves. When the question of one particular group is of relevance to all students, the professor gives an explanation to the whole class.

\section{RESULTS}

Paired-samples t-tests were conducted to determine whether there were any significant differences in students' evaluations of a course taught according to a traditional method and a cognitive apprenticeship method. There was significant agreement amongst the students that the course taught according to a cognitive apprenticeship method better facilitated their learning when compared to the course taught according to a traditional method. They also indicated that the cognitive apprenticeship method allowed them to better develop teamwork skills, included more efficient activities aimed at attaining the course objectives and helped them in developing critical analysis and logical reasoning skills. For other criteria, both teaching methods were evaluated by students as being comparable. In general, for both experiments, the cognitive apprenticeship method was rated as of better quality than the traditional method.

In order to determine whether these differences were contingent upon the students learning styles, correlations between each were carried out. It was found that the correlations between the learning styles and the relevant evaluation criteria were not significant. This suggests that the differences found in the students' evaluation of both courses are independent of the students' learning styles.

\section{DISCUSSION}

The core of the cognitive apprenticeship approach (modeling, coaching and scaffolding) was applied throughout the class sessions. It was found that, as the sessions progressed, students became more independent and acquired new knowledge and skills faster and with greater efficiency. Students had the opportunity to engage in collaborative practice in the kind of collaboration prevalent in real world civil engineering problem solving. Results of the two experiments showed that the cognitive apprenticeship approach used for teaching undergraduate civil engineering students was favored by most of the students, independent of their preferred learning style.

\section{REFERENCES}

1. Collins A, Brown J S, Holum A, American Educator 1991; 15(3); 6$11,38-46$.

2. Collins, A., Cambridge University Press 2006, 47-60.

3. Honey P, Mumford A, McGraw-Hill Book Company (UK) Ltd, 1992.

4. Lindsay E, Munt R, Rogers H, Scott D, Sullivan K, EEJ Higher Ed Academy Engineering Subject Centre 2008; 3(2); 28-36.

5. Lowery C A, EEJ Higher Ed Academy Engineering Subject Centre 2009, 4 (1); 52-60.

AFFILIATED INSTITUTIONS FOR CO-AUTHORS

*Department of Education, McGill University, Montreal, QC, Canada 